\title{
AXEL HONNETH E A LUTA POR RECONHECIMENTO
}

\author{
Marcela Borges Martinez ${ }^{1}$ \\ Instituto Federal de Educação, Ciência e Tecnologia do Rio de Janeiro (IFRJ) \\ https://orcid.org/0000-0001-5731-6565
}

\section{RESUMO:}

O reconhecimento é um conceito normativo. Ao reconhecermos alguém como portador de determinadas características ou capacidades, reconhecemos seu status normativo e estamos assumindo responsabilidade por tratar este alguém de determinada forma. $O$ não reconhecimento, neste caso, pode significar privação de direitos e marginalização; em uma democracia pode impossibilitar indivíduos ou grupos de desfrutar o ideal igualitário democrático, por exemplo. Nas últimas três décadas, a reflexão sobre esta categoria se aprofundou e assumiu maior importância no debate entre liberalismo e comunitarismo em paralelo às demandas, por vezes pelas conquistas, de grupos e minorias (LGBTQIA, portadores de necessidades especiais, feministas, indígenas, étnicos, etc.) que se sentem não reconhecidos e se engajam em movimentos políticos através de lutas por reconhecimento. Retomaremos, aqui, o desenvolvimento do conceito de "eticidade" empreendido por Axel Honneth em Luta por reconhecimento (1992), obra fundamental para a reflexão sobre o tema. $O$ autor situa sua teoria no meio termo entre a moral kantiana e as éticas comunitaristas: sua concepção é formal por entender que normas universais são condições de algumas possibilidades, mas é substantiva por se orientar pelo fim da autorrealização humana.

PALAVRAS CHAVE: Reconhecimento; Teoria crítica; Eticidade.

\section{AXEL HONNETH AND THE STRUGGLE FOR RECOGNITION}

\begin{abstract}
:
Recognition is a normative concept. By recognizing someone as having certain characteristics or capabilities, we recognize their normative status and we are taking responsibility for treating them in a certain way. Non-recognition, in this case, can mean deprivation of rights and marginalization; in a democracy may preclude individuals or groups from enjoying the democratic egalitarian ideal, for example. Over the past three decades, reflection on this category has deepened and taken on greater importance in the debate between liberalism and communitarianism parallel to the demands, sometimes for the achievements, of groups and minorities (LGBTQIA, people with special needs, feminist, indigenous, ethnic, etc.) who feel unrecognized and engage in political movements through struggles for recognition. We will return here to the development of Axel Honneth's concept of "ethical life" in Struggle for Recognition (1992), a fundamental work for reflection on the theme. The author places his theory in the middle between Kantian morality and communitarian ethics: his conception is formal for he understands that universal norms are conditions of some possibilities, but they are substantive for they are guided by the end of human self-realization.
\end{abstract}

KEYWORDS: Recognition; Critical theory; Ethical life.

1Doutora em Filosofia Moderna e Contemporânea pela Universidade do Estado do Rio de Janeiro (UERJ), Rio de Janeiro - Brasil e professora do Instituto Federal de Educação, Ciência e Tecnologia do Rio de Janeiro ( IFRJ), Rio de Janeiro - Brasil. E-mail: marcela.filosofia@gmail.com

MARTINEZ, Marcela Borges. Axel Honneth e a luta por reconhecimento. Griot : Revista de Filosofia, Amargosa, Bahia, v.16, n.2, p.148-168, dezembro/2017. 
A preocupação com a questão do reconhecimento concerne à era moderna, não tendo emergido antes como problema. É com Hegel que esta questão recebe tratamento específico e sua importância passa a ser universalmente reconhecida e identificada como uma modalidade adequada a uma sociedade democrática, bem como o entendimento de que sua negação ou recusa pode se caracterizar como forma de dominação. Não surpreende que Axel Honneth encontre neste autor os elementos necessários para seu projeto de fundamentação de uma teoria crítica da sociedade de teor normativo. $\mathrm{O}$ autor considera a luta por reconhecimento o elemento a partir do qual as identidades individual e coletiva se constituem e se movem. Para ele, há no conflito um potencial moral capaz de impulsionar o desenvolvimento da sociedade e essa interação se dá através de impulsos morais.

Em Luta por reconhecimento (1992) o autor desenvolve um conceito de "eticidade" próprio da teoria do reconhecimento. Seu percurso parte da reconstrução das linhas argumentativas de Hegel, prioritariamente do período em que lecionou em Jena, o que o leva a identificar três formas de reconhecimento. Com a ajuda da psicologia social de G. H. Mead, o autor demonstrará que o ser humano depende de três formas de reconhecimento para se relacionar consigo mesmo positivamente e que a cada uma delas corresponde uma forma de desrespeito, cuja experiência pode resultar em conflitos sociais. Seu objetivo é identificar em que medida experiências históricas de desrespeito se tornam generalizáveis, sinalizando uma lógica moral dos conflitos sociais.

Hegel critica as premissas atomísticas da tradição do direito natural, as quais pressupõem a existência de sujeitos isolados uns dos outros como base para a socialização humana. Esse atomismo impossibilita o desenvolvimento de um estado de união ética entre os homens capaz de originar uma sociedade eticamente integrada de cidadãos livres. $O$ autor tem em vista um estado de totalidade ética entre os homens, a qual pode ser comparada ao modelo político e institucional da polis grega, de onde extrai três características para representar sua concepção: 1) a vida pública como lugar de realização de todos os indivíduos em particular - unidade da liberdade universal e particular - e não como resultado da limitação dos espaços privados da liberdade; 2) a base para o exercício dessa liberdade ampliada não está na lei nem nas conviç̧ões morais, mas nos comportamentos praticados intersubjetivamente - nos costumes; 3 ) atividades ligadas ao mercado e a interesses particulares são consideradas parte do todo ético ${ }^{2}$.

A hipótese de Hegel é que a passagem da eticidade natural para uma sociedade organizada como totalidade ética não se dá através de um instrumento externo como um contrato, por exemplo, mas através da transformação e ampliação das formas sociais primitivas em relações abrangentes de interação social. A existência da diferença faz a eticidade passar de um estágio natural para uma unidade entre o universal e o particular através de um processo conflituoso. $O$ autor

\footnotetext{
2 A menção às linhas argumentativas de Hegel se faz necessária para a compreensão da concepção de eticidade apresentada por Axel Honneth. No entanto, é importante mencionar que não é objetivo deste estudo uma reconstrução histórica ou filosófica do pensamento hegeliano, apenas apontá-lo como origem de uma problematização fundamental aos estudos sobre o reconhecimento. $O$ conteúdo aqui apresentado refere-se à interpretação feita por Honneth na obra de 1992, onde o autor faz um estudo aprofundado da questão e disponibiliza ampla bibliografia.
} 
carrega a concepção aristotélica de sociabilidade humana natural com um potencial moral resultante agora de uma relação específica entre os homens: "[...] as coordenadas de seu pensamento filosófico-político se deslocam do conceito teleológico de natureza para um conceito social no qual uma tensão interna está constitutivamente incluída" (HONNETH, 2003, 47). Além da introdução deste domínio de tensão moral, Hegel reinterpreta o modelo hobbesiano de uma luta originária de todos contra todos introduzindo um conceito de luta social inédito, de acordo com o qual a luta para superar as relações éticas originárias não acontece pela mera autoconservação. Trata-se de um conflito essencialmente ético, pois clama pelo reconhecimento intersubjetivo da individualidade humana.

Em um segundo momento de seu período em Jena, Hegel se afastará do quadro de referências da teleologia aristotélica para desenvolver uma teoria filosófica da consciência. $O$ termo reconhecimento passará a se referir ao passo cognitivo que uma consciência idealmente constituída dá ao se reconhecer em outra consciência. No momento do "reconhecer-se no outro" há uma luta que proporciona a aquisição de um saber sobre se o outro também se reconhece nele como uma totalidade. A consciência de um indivíduo da totalidade acaba se cruzando com a de todos, formando uma consciência universal, absoluta, que será a base para uma coletividade futura e ideal. Trata-se do resultado de um processo de universalização mediado pelo reconhecimento recíproco. Veremos que tanto no primeiro como no segundo momento do pensamento hegeliano a luta por reconhecimento recebe lugar de destaque.

\section{Relações de reconhecimento na teoria social de Hegel}

Honneth inicia sua exposição retomando os passos da construção da teoria da sociedade hegeliana. Na etapa da eticidade natural, ele identifica duas relações de reconhecimento. Primeiramente a família: trata-se da relação entre pais e filhos que proporciona aos sujeitos reconhecerem-se como seres amantes e com carências, dependentes do outro para viver. Nessa fase, o trabalho de educação representa a negatividade do processo e a independência do filho, superando o estado simbiótico. A segunda etapa é a relação cognitivo-formal de reconhecimento do direito: as relações práticas particulares dos sujeitos com o mundo se transformam em pretensões de direito universais, contratualmente garantidas. Agora, os sujeitos se reconhecem como possíveis proprietários e com direito a realizar transações comerciais e, para isto, estabelecem relações jurídicas que determinam a liberdade negativa.

O próximo nível de integração seria a eticidade absoluta. No entanto, antes, há uma etapa de destruição dessas relações, ao que Hegel chama de crime. Trata-se de um exercício negativo da liberdade abstrata, conquistada nas relações jurídicas de reconhecimento, em função de os sujeitos se perceberem incluídos no convívio social apenas negativamente. ${ }^{3} \mathrm{Na}$ primeira etapa, antes da liberdade garantida juridicamente, estão atos de destruição, como "devastação" ou "aniquilação". Tratase de uma reação ainda indefinida a uma negação da eticidade que ainda não é

\footnotetext{
${ }^{3}$ De acordo com Honneth, Hegel não explora a questão da motivação do crime com profundidade. Porém, deixa indícios de que o motivo do criminoso se relaciona com a experiência do não reconhecimento.
} 
considerada propriamente como crime, no sentido de Hegel, pois ainda não existe neste momento a liberdade juridicamente reconhecida. A segunda etapa do crime é o roubo a outra pessoa. No ato do roubo um sujeito é atingido no seu direito à propriedade, juridicamente garantido, mas também como pessoa, uma vez que ainda falta à garantia jurídica a força da imposição da autoridade pública, "[...] todo sujeito tem que preocupar-se sozinho com a defesa de seus direitos e, por isso, é ameaçado em toda sua identidade pelo furto" (HONNETH, 2003, 54). Nesse ponto, se inicia uma série de reações, às quais Hegel confere o conceito de luta. Para Hegel, esta luta tem resultado pré-definido, pois o sujeito lesado luta por sua pessoa inteira, enquanto o criminoso tem por objeto apenas um interesse particular. Assim, o primeiro prevalece sobre o segundo. A terceira etapa, por fim, é a luta por honra, a qual se inicia com o roubo e termina com a sujeição dos criminosos. Aqui há a exigência de um rompimento intersubjetivo, o qual tem por fundamento e causa a violação da integridade de uma pessoa em seu todo e não de uma pretensão de direito individual apenas. A honra é uma atitude positiva que adotamos em relação a nós mesmos, em função de nossas qualidades e particularidades. No entanto, essa relação afirmativa de um indivíduo consigo mesmo depende do reconhecimento de suas qualidades por seus parceiros de interação. $O$ conflito gerado pela busca da reparação da honra começa na ofensa e culmina com a luta de vida e morte, ou seja, para além das pretensões juridicamente cobráveis, pois o que está em jogo é a totalidade de uma pessoa.

Segundo Honneth, Hegel quer demonstrar que através desses atos de destruição se formam relações de reconhecimento mais profundas e maduras capazes de mediar a integração social. Primeiramente há um aumento de saber sobre a própria identidade de cada sujeito, tanto como pessoa jurídica como de sua subjetividade particular. Um segundo aspecto evolutivo é o alcance de maior autonomia, o que leva ao reconhecimento pelos sujeitos de sua dependência recíproca - o conflito passa da luta por honra entre indivíduos particulares para o confronto entre comunidades sociais, pois os sujeitos agora fazem parte de um todo. No processo dessas duas dimensões evolutivas acontece a passagem da eticidade natural para a eticidade absoluta, que é a relação de reconhecimento do Estado, baseada no reconhecimento afetivo, superior ao reconhecimento cognitivo. Hegel utiliza o conceito intuição recíproca, Honneth traduz por solidariedade. É esta solidariedade que pode servir de base comunicativa para que sujeitos, antes isolados por relações jurídicas, possam voltar a se integrar coletivamente.

Em um segundo momento de seu período em Jena, ao redirecionar seu projeto com o objetivo de desenvolver uma filosofia do espírito, Hegel redefine seus propósitos. Agora, o processo de socialização é uma construção gradual que acontece do espírito subjetivo, passando pelo espírito efetivo e chega ao espírito absoluto. Honneth destaca que, mais uma vez, Hegel inclui o modelo estrutural social da luta por reconhecimento na primeira fase de formação da sociedade, fazendo dele a força motriz para o desenvolvimento de uma comunidade ética e, até mesmo, do espírito absoluto.

Na etapa do espírito subjetivo, a reflexão gira em torno de quais experiências um sujeito deve ter vivido para conceber-se como uma pessoa dotada de direitos e poder participar da vida institucionalmente regulada de uma sociedade, isto é, do 
espírito efetivo. A vontade, entendida aqui como capacidade de resolução, é a pedra de toque das relações práticas do sujeito com o mundo. O espírito subjetivo, considerado primeiramente como inteligência, em função da relação puramente cognitiva que estabelece com a realidade, se torna vontade quando passa a ter uma experiência prática com a realidade, não mais apenas teórica. As etapas do aspecto prático do processo da consciência individual começam com a autoexperiência instrumental do sujeito - trata-se do nexo interno entre trabalho, instrumento e produto. Através do trabalho o sujeito supera a relação cognitiva com a realidade, pois percebe que é capaz de construir a realidade praticamente. No entanto, o trabalho representa uma autonomia limitada, pois se realiza apenas sob a coação da autodisciplina. Assim, a vontade instrumental, por permitir apenas que o espírito subjetivo se perceba como "coisa ativa", não é uma experiência capaz de gerar uma consciência de si como de uma pessoa de direito. Hegel buscará uma dimensão complementar à relação prática com o mundo numa primeira forma de reconhecimento recíproco, isto é, uma dimensão intersubjetiva da vontade, que será o reconhecimento do amor.

De acordo com Honneth, a argumentação de Hegel vai além da hipótese da teoria da socialização segundo a qual o reconhecimento intersubjetivo é fundamental para a formação da identidade do sujeito. Sua consideração é de que o indivíduo que não reconhece seu parceiro como um gênero de pessoa determinado, não pode experienciar integralmente a si mesmo como o mesmo gênero de pessoa, pois está negando ao parceiro as propriedades e capacidades em que quis se sentir confirmado por ele. Existe nessa forma de reconhecimento uma pressão para a reciprocidade, mesmo que este não seja exatamente o que Hegel busca com o reconhecimento do amor, mas sim sua função no processo de formação da autoconsciência de uma pessoa de direito.

Hegel apresenta o amor como um "pressentimento da eticidade", não como ela mesma. No entanto, se o sentido negativo for invertido, pode-se perceber detalhes sobre a função desempenhada pelo reconhecimento do amor no processo de formação do sujeito como parte das condições necessárias para um desenvolvimento do ego bem sucedido: "[...] só o sentimento de ser reconhecido e aprovado fundamentalmente em sua natureza instintiva particular faz surgir num sujeito de modo geral a medida da autoconfiança que capacita para a participação igual na formação política da vontade" (HONNETH, 2003, 79-80). Assim, a relação de reconhecimento do amor pode ser a forma de integração de uma comunidade ética e, também, a relação afetiva entre homem e mulher (a qual terá sua expressão máxima na figura do filho). Porém, a relação amorosa de uma família ainda não é suficientemente complexa para que os sujeitos sejam abalados por conflitos que os levem a regular sua convivência através de normas gerais, sem as quais eles não conseguem ter uma consciência de si mesmo como uma pessoa portadora de direitos.

A segunda forma de reconhecimento necessária é o reconhecimento do direito, das relações jurídicas. Podemos conceder, sem muitos problemas, que a coexistência de diversas famílias (cada uma formando uma totalidade) demanda a necessidade de organização espacial e econômica de uma comunidade. Esta é uma primeira forma de convívio, ou concorrência social, característica das teorias do direito natural. $O$ problema dessas teorias, para Hegel, é simples, dizendo respeito à seguinte questão: 
como indivíduos em uma situação social marcada por relações de disputa recíproca chegam à ideia de direitos e deveres intersubjetivos? De acordo com o autor, o erro dos autores da tradição do direito natural foi buscar a determinação do direito fora das relações práticas, ${ }^{4}$ quando direito é relação, limitação das liberdades. Hegel se concentrará nas relações pré-contratuais de reconhecimento recíproco, pois nelas é possível encontrar o potencial moral que depois se realiza positivamente na disposição individual de limitação mútua das liberdades.

Diferentemente de Hobbes, o conflito pela tomada de propriedade é descrito por Hegel como uma luta por reconhecimento e não por autoafirmação. $O$ indivíduo reage por ser ignorado pelo outro. Ao se sentir assim, lesa a outra parte, não para satisfazer suas necessidades, mas para recuperar a atenção do outro. No indivíduo atacado, a percepção se altera no sentido de que agora ele está para sempre vinculado ao outro, pois foi obrigado a rever sua posição inicial egocêntrica. Essa aceitação mútua do parceiro de interação representa um acordo implícito entre os indivíduos, o qual é anterior ao conflito. A produção intersubjetiva da relação jurídica se dá através da experiência da morte - uma luta de vida e morte. A consciência reciproca da mortalidade faz com que os sujeitos que lutam percebam que "[...] eles já se reconheceram previamente em seus direitos fundamentais e que dessa forma já criaram implicitamente o fundamento social para uma relação jurídica intersubjetivamente vinculante" (HONNETH, 2003, 94).$^{5}$

Vemos, assim, que a luta por reconhecimento contribui para o processo de formação do elemento espiritual da sociedade civil e também atua como uma pressão normativa para a geração do direito. $O$ reconhecimento jurídico tem como forma universal o contrato, a expressão da vontade geral. Em paralelo, associada ao contrato como etapa de concreção do reconhecimento jurídico, está seu inverso, a injustiça, a quebra da promessa. Surge agora a coerção legítima como o caminho para a correção deste desvio para fora do contrato, pois a sociedade ordenada por relações jurídicas pode obrigar o sujeito a cumprir suas obrigações contratuais.

De acordo com Honneth, Hegel não trata dos progressos nem da estrutura do reconhecimento jurídico. O que é introduzido com a motivação moral do crime é a passagem do direito natural para o direito positivo, isto é, o direito deixa de ser uma relação informal e passa a ser regulado pelo Estado. Esta passagem tem como elo a penalidade e entra em jogo a lei como forma objetivada da normatividade comum. Esta é responsável por regular formalmente as relações jurídicas entre indivíduos através da ameaça de sanções do Estado. Todavia, Honneth avalia que Hegel não aprofunda com o rigor necessário as possibilidades abertas para uma interpretação do crime, fazendo "[...] a proposta de atribuir mais uma vez o próprio desenvolvimento da relação jurídica à pressão de uma luta por reconhecimento permanecer, no todo do seu texto, apenas uma simples sugestão" (HONNETH, 2003, 105).

A terceira forma de reconhecimento é a eticidade. De acordo com Honneth, a teoria do reconhecimento deveria apresentar um conceito de eticidade que tivesse

\footnotetext{
${ }^{4}$ Hobbes usa um preceito da prudência, Kant usa um postulado da moral.

5 De acordo com Honneth, no entanto, Hegel não esgota a questão, deixando muitas arestas no desenvolvimento dessa etapa da formação do espírito subjetivo, apesar de tê-la tratado inequivocamente, o que gerou uma série de leituras e interpretações.
}

MARTINEZ, Marcela Borges. Axel Honneth e a luta por reconhecimento. Griot : Revista de Filosofia, Amargosa, Bahia, v.16, n.2, p.148-168, dezembro/2017. 
como pressuposto a ideia "[...] de que a integração social de uma coletividade política só pode ter êxito irrestrito na medida em que lhe correspondem, pelo lado dos membros da sociedade, hábitos culturais que têm a ver com a forma de seu relacionamento recíproco" (HONNETH, 2003, 108). Porém, Hegel estabelece a teoria da eticidade com categorias que se referem às relações entre os membros da sociedade com o Estado, não em relações interativas. $O$ problema está em que os hábitos culturais que se fundam nessa relação de autoridade assumem o papel que antes era preenchido por formas mais exigentes de reconhecimento recíproco. Agora a fundação do Estado passa a ser justificada pelo poder tirânico daqueles com capacidade de liderança e carisma, não é mais atribuída a um processo de conflito intersubjetivo, como se dava no aparecimento da relação jurídica. O cidadão eticamente formado desempenha dois papéis, bourgeois e citoyen. Enquanto burguês, o indivíduo persegue seus interesses particulares através de relações juridicamente reguladas. Enquanto cidadão, ele participa da formação política da vontade. O primeiro estabelece relações intersubjetivas de reconhecimento jurídico, o segundo se relaciona com o universal superior do Estado.

Para Honneth, a filosofia da consciência obscurece a teoria do reconhecimento e a possibilidade de um conceito intersubjetivista de eticidade, levando Hegel a abandonar o programa de Jena: "[...] dito brevemente, a eticidade tornou-se uma forma do espírito constituindo-se monologicamente e já não compõe uma forma particularmente exigente de intersubjetividade" (HONNETH, 2003, 112). Na Fenomenologia do espírito (1807), que encerra seu trabalho em Jena, a luta por reconhecimento é responsável unicamente por formar a autoconsciência, representada na dialética do senhor e do escravo, ligada à experiência prática do trabalho. Se houve ganho metodológico na nova fase, o autor acabou se desviando do modelo de luta por reconhecimento como força moral capaz de impulsionar o movimento de socialização do espírito.

Além do fato de ter sido abandonada prematuramente, a teoria do reconhecimento hegeliana apresenta outras dificuldades. Seu projeto se funda em premissas metafísicas insustentáveis no que se refere às linhas teóricas do pensamento atual que, como consequência da crítica ao idealismo da razão, utiliza um conceito de razão mundanizado e vinculado à experiência. O programa de Jena apresenta uma reconstrução da formação ética da humanidade de forma que, através das etapas conflituosas, aflora um potencial moral constituinte das relações comunicativas entre indivíduos. Porém, Hegel não está falando de um processo mundano, mediado pela luta, mas de um processo objetivo da razão: na primeira fase, o processo se desdobrava no pressuposto aristotélico da natureza comunitária do homem; em um segundo momento, com base nos fundamentos da filosofia da consciência da autorrelação do espírito; "[...] suas construções, por mais que nos escritos de Jena sejam concretas e mesmo próximas da ação, tomam de empréstimo uma grande parte de suas condições de validade da certeza metafísica de fundo acerca do processo englobante da razão" (HONNETH, 2003, 118).

Honneth pretende conduzir uma reconstrução atualizadora do sistema hegeliano pelo prisma de uma teoria social normativa, no sentido do desenvolvimento moral das sociedades, e que considere que as relações intersubjetivas estão inseridas no mundo social. Para cumprir o desafio, o autor se 
coloca três tarefas: a) reconstruir, à luz de uma psicologia social fundamentada empiricamente, a primeira tese hegeliana de que a formação do $E u$ prático está ligada à pressuposição do reconhecimento recíproco entre dois sujeitos; b) através de uma fenomenologia das formas de reconhecimento, conduzida empiricamente, avaliar e corrigir a segunda tese hegeliana: de que as três formas de reconhecimento o amor, o direito e a "eticidade" - são relações de reconhecimento gradativas em que os indivíduos se percebem como pessoas autônomas e individualizadas; e c) comprovar a terceira tese de Hegel de que a formação das três formas de reconhecimento se dá através de uma lógica mediada por etapas de uma luta moral, onde cada avanço no processo de comunitarização impulsiona os sujeitos ao conflito intersubjetivo, o que resulta na confirmação social, até então não assegurada, de sua pretensão de autonomia. Honneth examinará as hipóteses separadamente: a ideia de uma série de etapas de reconhecimento se sustenta empiricamente? É possível vincular a cada forma de reconhecimento uma forma de desrespeito social? Existem comprovações históricas e sociológicas de que essas formas de desrespeito social possuem força motriz para conflitos sociais?

\section{A psicologia empírica de G. H. Mead}

A psicologia social de George Herbert Mead oferece uma possibilidade de atualização da teoria hegeliana em termos pós-metafísicos. Mead apresenta uma concepção naturalista da teoria de que os sujeitos formam sua identidade através da experiência de um reconhecimento intersubjetivo. $\mathrm{O}$ autor compartilha com Hegel a ideia de que a luta por reconhecimento pode ser a pedra fundamental para uma teoria que vise explicar a evolução moral da sociedade. Aposta em uma psicologia empírica que possa ampliar nosso conhecimento a respeito das operações cognitivas do ser humano na resolução de problemas e das expectativas normativas referentes à solução intersubjetiva de conflitos: "[...] o processo de socialização em geral se efetua na forma de uma interiorização das normas de ação, provenientes da generalização da expectativa de comportamento de todos os membros da sociedade" (HONNETH, 2003, 135). As normas interiorizadas determinam de maneira justificada as expectativas e obrigações recíprocas.

No processo do desenvolvimento social, a identidade se constrói e o sujeito passa a se reconhecer como participante de uma sociedade regulada através da divisão do trabalho. É através da relação de reconhecimento mútuo que o indivíduo se percebe como parte de uma coletividade, pois ao reconhecer outras identidades o sujeito se sente também reconhecido pela coletividade. Ao assumir a perspectiva do "outro generalizado", tanto na compreensão que possui de si mesmo quanto na assunção de normas sociais de ação, o indivíduo passa a se compreender como uma pessoa que possui direitos, "[...] direitos são de certa maneira as pretensões individuais das quais posso estar seguro que o outro generalizado as satisfará" (HONNETH, 2003, 137). É a concessão de direitos que dá a alguém o status de pertencer a uma comunidade, o portador de direito é reconhecido como membro da sociedade. Segundo Honneth, apesar de faltar à concepção de Mead uma ponte de referência com a etapa do amor de Hegel, a concepção do "outro generalizado" complementa e aprofunda o conceito geral de direito hegeliano: "[...] reconhecer-se 
reciprocamente como pessoa de direito significa que ambos os sujeitos incluem, em sua própria ação, como efeito de controle, a vontade comunitária incorporada nas normas intersubjetivamente reconhecidas de uma sociedade" (HONNETH, 2003, 138). Esta forma de reconhecimento representa um modo de autorrelação prática, para o qual Mead usará o conceito de autorrespeito.

Mead concorda com Hegel em mais um ponto fundamental. Para ele, a relação jurídica de reconhecimento só estará completa se, além da confirmação de cada indivíduo como membro de uma sociedade, puder expressar as diferenças individuais entre os membros da mesma. $O$ autor introduz uma tensão entre a vontade geral e o desejo de individuação que levará a um conflito moral entre indivíduo e sociedade. Isto faz com que o sujeito reivindique novas formas de reconhecimento social e um maior número de direitos à liberdade, o que resultará em um processo de evolução social, pois cada etapa acontece através de um ganho de autonomia individual.

\begin{abstract}
Assim, como Hegel em relação ao processo de formação da 'vontade comum', Mead concebe a evolução moral das sociedades como um processo de liberação gradual dos conteúdos do reconhecimento jurídico [...]. Mas, diferentemente de Hegel, Mead oferece para o processo evolutivo assim circunscrito uma explicação que o torna transparente em seus fundamentos motivacionais. [...] Porque os sujeitos, sob a pressão de seu 'Eu' são compelidos a uma deslimitação contínua das normas incorporadas no 'outro generalizado', eles se encontram de certo modo sob a necessidade psíquica de engajar-se por uma ampliação da relação de reconhecimento jurídica; a práxis social que resulta da união de esforços por um tal 'enriquecimento da comunidade' é o que se pode chamar, na psicologia social de Mead, 'luta por reconhecimento' (HONNETH, 2003, 135).
\end{abstract}

Para Mead, entretanto, é necessário dar um passo a mais em direção à próxima etapa da individuação - a autorrealização - e isso depende de uma forma especial de reconhecimento. Trata-se de um reconhecimento valorativo, através do qual o sujeito se convence do valor que suas capacidades e propriedades possuem para o ambiente social. Por depender do outro, esta aprovação, que requer perceberse a si próprio em sua unicidade individual, se refere a uma autocertificação ética baseada em conteúdos axiológicos coletivos.

De acordo com Honneth, Mead não dá prosseguimento às questões relativas ao processo de autorrealização. Ele não esclarece qual forma de reconhecimento recíproco se faz necessária quando se trata da certificação de particularidades e não mais de concessão intersubjetiva de direitos. A abordagem da relação social capaz de conferir reconhecimento por particularidades é feita pelo ponto de vista do vínculo entre autorrealização e divisão social do trabalho. Com efeito, este sistema transparente de divisão funcional do trabalho é, segundo Honneth, uma resposta pós-tradicional ao problema hegeliano da eticidade. Todavia, o modelo utilizado por Mead, ao realçar o vínculo entre divisão social do trabalho e autorrealização, não permite que o sujeito alcance independência individual em relação às finalidades coletivas, pois o trabalho útil e bem realizado se define através de uma concepção de boa vida e não é, portanto, axiologicamente neutro. Desta forma, o indivíduo não tem a dimensão particular de sua contribuição social.

MARTINEZ, Marcela Borges. Axel Honneth e a luta por reconhecimento. Griot : Revista de Filosofia, Amargosa, 
Por conseguinte, a dificuldade que Mead de fato abordou, mas para depois voltar a ignorar, consiste na tarefa de dotar o 'outro generalizado' com um common good, que faz todos os sujeitos conceberem igualmente seu próprio valor para a coletividade, sem impedi-los por isso da realização autônoma do seu Self; pois só uma semelhante forma de eticidade, por assim dizer democrática, abriria o horizonte cultural no qual os sujeitos, com direitos iguais, poderiam reconhecer-se reciprocamente em sua particularidade individual pelo fato de que cada um deles é capaz de contribuir, à sua própria maneira, para a reprodução da identidade coletiva (HONNETH, 2003, 152-153).

Em comparação à concepção formal de eticidade de Hegel, Mead avança na reflexão sobre os problemas relacionados à questão da motivação ao considerar que falta uma indicação de que os sujeitos se engajarão em atitudes e sentimentos solidários, o que só parece possível a partir de uma experiência existencial de que precisamos uns dos outros. Através da psicologia social de Mead, também foi possível atualizar a teoria hegeliana do reconhecimento para um quadro teórico com equivalentes naturalistas e pós-metafísicos. Honneth partirá, agora, para a derivação de um conceito formal de eticidade, a partir das ideias dos dois autores, tentando preencher as lacunas deixadas em aberto. Mas o que seria um conceito formal de boa vida? Para o autor, não se trata simplesmente das convicções axiológicas formadoras do ethos de uma comunidade, mas "[...] dos elementos estruturais da eticidade, que, sob o ponto de vista universal da possibilitação comunicativa da autorrealização, podem ser distinguidos normativamente da multiplicidade de todas as formas de vida particulares (HONNETH, 2003, 271). Sua abordagem não pretende realizar apenas a autonomia moral do ser humano, mas sua autorrealização como um todo, fazendo da moral mais um dos mecanismos de proteção deste processo. Assim, sua reflexão se posiciona no centro do debate entre liberalismo e comunitarismo, sendo seu propósito a elaboração de uma teoria da sociedade que possa, através das pretensões normativas inscritas nas relações de reconhecimento recíproco, esclarecer os movimentos de transformação social.

\section{Formas de reconhecimento: amor, direito e solidariedade}

O próximo passo de Honneth será clarificar a tripartição feita por Hegel e Mead das formas de reconhecimento tentando demonstrar, através da pesquisa empírica, em que medida tal estrutura corresponde às relações da vida social. Em seguida, o autor abordará as experiências sociais responsáveis pelo surgimento das lutas por reconhecimento, um ponto que não foi sistematizado pelos dois autores anteriores: às três formas de reconhecimento correspondem três formas de violação, de desrespeito, cuja experiência pode resultar em conflitos sociais. Sua hipótese é de que as três esferas se distinguem entre si de tal maneira que também serão independentes "[...] no que concerne ao medium do reconhecimento, à espécie de autorrelação possibilitada e ao potencial de desenvolvimento moral (HONNETH, 2003, 159).

A primeira forma de reconhecimento, o amor, deve ser entendida da forma mais neutra possível, isto é, como relações primárias de ligação emotiva intensa, tais 
como as relações eróticas, de amizade e familiares. Para transferir esse tema para um contexto de pesquisa, Honneth se vale da ideia hegeliana de que o amor é um "ser-simesmo em um outro", ou seja, depende de equilíbrio frágil entre autonomia e ligação. Esse tema é de interesse da teoria psicanalítica das relações de objeto, a qual trabalha com a importância das experiências interativas na primeira infância e considera que a relação afetiva com outras pessoas organiza as pulsões libidinosas e propicia amadurecimento. ${ }^{6}$

Para confirmar a ideia, já intuída em Hegel, de que o sucesso das relações afetivas depende da capacidade, adquirida na infância, de equilibrar simbiose e autoafirmação, Honneth se baseará nos estudos de Donald W. Winnicott. Segundo este autor, a criança, nos primeiros meses de vida, está de tal forma conectada à mãe que não pode ser considerada um objeto de pesquisa independente. A mãe e o bebê estão fundidos em uma relação de simbiose. Em um segundo estágio, a relação se altera e de simbiose passa a uma dependência relativa. Nessa etapa, a mãe retoma rotinas cotidianas e, paralelamente, a criança cresce intelectualmente, passando a diferenciar cognitivamente o próprio ego e o ambiente. Isso possibilita um primeiro passo no processo de autonomização e tanto a criança como a mãe podem se conscientizar de uma relação de amor independente, não mais simbiótica. Há, nesse momento, uma experiência de reconhecimento da independência individual do outro e, também, de confiança. A experiência do amor propicia uma segurança emotiva que se faz fundamental para todas as outras atitudes de autorrespeito e autoconfiança necessárias à participação autônoma na vida pública.

Com relação à forma de reconhecimento do direito, encontramos, tanto em Hegel como em Mead, o entendimento de que só chegamos à compreensão de nós mesmos como portadores de direitos na medida em que possuímos um saber sobre nossas obrigações recíprocas com o outro. De acordo com Hegel, a forma de reconhecimento do direito tem por objetivo a constituição das relações jurídicas modernas, as quais se estendem, por princípio, a todos os homens na qualidade de seres livres e iguais, ou seja, esta forma de reconhecimento é responsável por assegurar a autonomia individual dos sujeitos. Mead, por sua vez, através do conceito de "outro generalizado", estava visando apenas à lógica do reconhecimento jurídico. Tratava-se da ideia básica de que todo ser humano pode ser considerado portador de alguns direitos ao ser reconhecido como membro de uma sociedade, sem indicar, no entanto, qual espécie de direitos e como eles se fundamentam. $O$ problema é que o conceito mitigado de ordem jurídica, apresentado por Mead, carece de normatividade, pois através dele o indivíduo alcança reconhecimento apenas como membro de uma sociedade que se organiza pela divisão do trabalho.

Uma forma tradicional de reconhecimento jurídico dessa espécie, já concede ao sujeito, como vimos, uma proteção social para sua 'dignidade' humana; mas está ainda inteiramente fundida com o papel social que lhe compete no quadro de uma distribuição de direitos e encargos amplamente desigual (HONNETH, 2003, 181).

\footnotetext{
6 Na obra de 1992, Honneth oferece uma ampla bibliografia na área da psicanálise, especialmente as obras
} de Donald W. Winnicott. 
Para Hegel, diferentemente do amor, a forma de reciprocidade específica do direito só pode se constituir no percurso de uma evolução histórica. Nas relações jurídicas de sociedades tradicionais, o status de pessoa de direito esta conectado ao status social, isto é, ao grau de estima social de determinado papel na sociedade. Sabemos que com a passagem à modernidade as relações jurídicas são submetidas a exigências mais rigorosas, no sentido de que todo sujeito, na mesma medida, deve ser reconhecido como pessoa de direito. Com efeito, a estrutura hegeliana é uma forma mais exigente no que respeita à reciprocidade, pois visa à legitimidade da ordem jurídica moderna, a qual se baseia em um acordo racional entre indivíduos.

[...] obedecendo à mesma lei, os sujeitos do direito se reconhecem reciprocamente como pessoas capazes de decidir com autonomia individual sobre normas morais. Diferentemente das definições de Mead, as de Hegel, só valem para a ordem social do direito na medida em que esta pode se desligar da autoridade natural de tradições éticas, adaptando-se ao princípio de fundamentação universalista (HONNETH, 2003, 182).

Assim, duas formas semânticas do termo respeito se revelam: o reconhecimento jurídico - ligado ao direito - e a estima - forma de reconhecimento de uma comunidade de valores. Uma das formas é o respeito moral conferido pelo reconhecimento jurídico da nossa universalidade como seres humanos; a outra forma é a estima social conferida ao indivíduo em função do valor de suas particularidades. Na primeira, importa qual a propriedade universal pela qual os sujeitos se respeitam; na segunda, importa o sistema valorativo de referência.

A propriedade universal reconhecida e assegurada através do status de pessoa de direito é a imputabilidade moral. Uma vez que a ordem jurídica só se justifica através da possiblidade do assentimento de todos aqueles a quem ela se destina, "[...] é preciso supor nesses sujeitos de direito a capacidade de decidir racionalmente, com autonomia individual, sobre questões morais" (HONNETH, 2003, 188). No entanto, o que faz com que uma pessoa seja considerada capacitada para "agir autonomamente com discernimento racional" depende de como se define o procedimento do acordo legitimador. Portanto, "[...] a definição das propriedades que caracterizam constitutivamente o ser humano como pessoa depende das assunções de fundo acerca dos pressupostos subjetivos que capacitam para participação na formação racional da vontade" (HONNETH, 2003, 188).

Honneth demonstra, através de um panorama da evolução histórica do sistema de direitos em condições pós-tradicionais, como o alargamento das pretensões jurídicas individuais nas sociedades modernas representou uma ampliação das propriedades universais de uma pessoa moralmente imputável. Se tomarmos em comparação o começo do desenvolvimento do direito moderno, veremos que houve um ganho na esfera do reconhecimento mútuo do outro como pessoa de direito, pois há uma maior pressão para liberdades, igualdade e inclusão. $O$ autor fala em duas possibilidades evolutivas: por um lado, há a possibilidade de diferenciação individual nas oportunidades de realização das liberdades garantidas socialmente; e, por outro lado, há uma pressão de universalização por via de um alargamento no círculo de grupos alcançados pelo direito. Esse potencial evolutivo faz com que os conflitos, resultantes da experiência do desrespeito ou da negação de reconhecimento, se 
transformem em reivindicações de ampliação do status de uma pessoa de direito, isto é, os indivíduos conquistam mais classes de direitos e esses direitos são estendidos a um número cada vez maior de membros da sociedade.

Se na relação amorosa a autorrelação positiva alcançada é a autoconfiança, na relação jurídica a autorrelação prática possibilitada é o autorrespeito. É através do reconhecimento jurídico que o indivíduo adulto percebe que sua ação é a manifestação de sua autonomia e que é respeitada por todos. Essa autorrelação é alcançada com a formação de direitos básicos universais, os quais asseguram igualdade e liberdade a todos, pois a possibilidade de reclamar um direito representa simbolicamente para o sujeito a possibilidade de ser reconhecido universalmente como pessoa moralmente imputável.

[...] um sujeito é capaz de se considerar, na experiência do reconhecimento jurídico, como uma pessoa que partilha com todos os outros membros de sua coletividade as propriedades que capacitam para a participação numa formação discursiva da vontade; e a possibilidade de se referir positivamente a si mesmo desse modo é o que podemos chamar de "autorrespeito"(HONNETH, 2003, 197).

Tanto Hegel como Mead chegaram a três formas de reconhecimento recíproco: a experiência afetiva, o reconhecimento jurídico e a estima social. No respeita à terceira forma de reconhecimento, vimos que Hegel a introduz através do conceito de "eticidade" e Mead o faz através da ideia de divisão cooperativa do trabalho. Em ambos os casos, é necessário um horizonte de valores e objetivos compartilhados através dos quais os indivíduos possam medir o valor social de suas contribuições. O problema é, se a estima social se define pelos critérios determinados pela autocompreensão cultural de uma sociedade, como se evitar assimetrias e exclusão de grupos? Como se evitar a veiculação de modelos ideológicos ou formas de perfeccionismo? Como a estima social pode manter a universalidade alcançada através do reconhecimento jurídico? Para Honneth, seu "[...] alcance social e a medida de sua simetria dependem então do grau de pluralização do horizonte de valores socialmente definido, tanto quanto do caráter dos ideais de personalidade aí destacados" (HONNETH, 2003, 200). Como o universo de valores é o que determina o devido reconhecimento, ele pode ser mais aberto a formas distintas de autorrealização, porém, pode também ser um sistema predominante de estima.

Destarte, a estima acaba por promover relações assimétricas de reconhecimento, pois sua conquista está sempre atrelada aos objetivos abstratos da sociedade, à possibilidade de atrair a opinião pública, a padrões de distribuição de renda, a possíveis desigualdades, portanto. É por isso que Honneth vai recomendar a categoria de solidariedade como uma forma específica de estima. $\mathrm{O}$ autor considera que houve uma evolução histórica desta forma de reconhecimento, similar à que houve com o direito. Nas sociedades feudais, os indivíduos eram avaliados pelas características da coletividade, não por suas características individuais. Tanto mais valor social ele teria quanto mais contribuísse coletivamente. Nesse cenário, a autorrelação prática alcançada pelos indivíduos é "um sentimento de orgulho de grupo ou de honra coletiva" que faz com que se desenvolvam relações solidárias entre os membros que se estimam reciprocamente e compartilham determinados objetivos

MARTINEZ, Marcela Borges. Axel Honneth e a luta por reconhecimento. Griot : Revista de Filosofia, Amargosa, 
coletivos; a solidariedade se desenvolve como uma tomada de interesse recíproco por modos de vida distintos.

Com a passagem à modernidade e com a complexificação e dessacralização das sociedades, a ordem social não poderá mais ser regulada de forma axiológica. A partir desse momento, não se pode mais determinar quais formas de conduta são eticamente admissíveis ou preferíveis; desta forma, a estima social passa a ser medida pelo que o indivíduo tem de particular, não mais por propriedades coletivas. Essa individualização desencadeia um processo de transformação histórica dos conceitos: o que no feudalismo era honra, passa, na modernidade, a reputação ou prestígio, categorias através das quais se medirá a estima de um indivíduo. Assim, a estima social se desvincula do padrão de reconhecimento do direito, onde a universalização jurídica fez a honra se transformar em dignidade e a privatização da honra levou à ideia de integridade subjetiva. Diferentemente, a estima tem relação com o reconhecimento social da autorrealização individual de alguém, por ser esta autorrealização valiosa para a sociedade. A autorrelação prática que o sujeito alcança com este reconhecimento é o sentimento de autoestima. Segundo Honneth, quando "[...] todo membro de uma sociedade se coloca em condições de estimar a si próprio dessa maneira, pode-se falar então de um estado pós-tradicional de solidariedade social" (HONNETH, 2003, 210).

Não é isenta de problemas a caracterização genérica do conceito de solidariedade feita por Honneth. Segundo o autor, para haver solidariedade em sociedades pós-tradicionais, é necessário que sujeitos individualizados e autônomos se estimem simetricamente, isto é, que os sujeitos se considerem de maneira recíproca "[...] à luz de valores que fazem as capacidades e as propriedades do respectivo outro aparecer como significativas para a práxis comum" (HONNETH, 2003, 210). Simetria significa, aqui, a chance que todo indivíduo recebe de "[...] sem graduações, experienciar a si mesmo, em suas próprias realizações e capacidades, como valioso para a sociedade" (HONNETH, 2003, 211). Quando esta forma de relação solidária se realiza, é possível que surja uma disputa por estima livre de dor ou desrespeito. Honneth diz ainda que essas relações são consideradas solidárias "[...] porque elas não despertam apenas a tolerância para com a particularidade individual de outra pessoa, mas o interesse afetivo por essa particularidade [...]"(HONNETH, 2003, 211, grifo nosso).

\section{Formas de desrespeito: violação, privação e degradação}

A distinção dos três níveis de reconhecimento e das respectivas autorrelações positivas que eles proporcionam abre espaço para a investigação sobre o aspecto negativo relacionado a cada um deles. Isto é, qual será a experiência vivida por aqueles que são desrespeitados ou que têm o reconhecimento pretendido negado? De que maneira se altera a autorrelação prática de uma pessoa nessas condições? Honneth diz que determinar estes níveis de desrespeito é necessário para que se aborde a questão fundamental deixada em aberto por Hegel e Mead: de que maneira "[...] a experiência do desrespeito está ancorada nas vivências afetivas dos sujeitos humanos, de modo que se possa dar, no plano motivacional, o impulso para a resistência social e para o conflito, mais precisamente, para uma luta por 
reconhecimento?" (HONNETH, 2003, 214). Os seres humanos carregam uma vulnerabilidade associada ao conceito de desrespeito, pois há nessa experiência o risco de um trauma capaz de abalar a identidade da pessoa.

[...] na autodescrição dos que se veem maltratados por outros, desempenham até hoje um papel dominante categorias morais que, como a 'ofensa' ou o 'rebaixamento', se referem a formas de desrespeito, ou seja, a formas de reconhecimento recusado. Conceitos negativos dessa espécie designam um comportamento que não representa uma injustiça só porque ele estorva os sujeitos em sua liberdade de ação ou lhes inflige danos; pelo contrário, visa-se àquele aspecto de um comportamento lesivo pelo qual as pessoas são feridas numa compreensão positiva de si mesmas, que elas adquiriram de maneira intersubjetiva (HONNETH, 2003, 213).

A primeira forma de desrespeito abordada por Honneth é aquela causada pela violação e tortura. Este modo de desrespeito destrói a forma mais originária de autorrelação prática - a confiança em si mesmo. $O$ sofrimento da pessoa que sente a humilhação de ter sua vontade subjugada pela de outra pessoa extrapola a dor corporal e pode chegar à perda do senso de realidade. Esta experiência não varia simplesmente com o quadro histórico cultural de referências. Não é uma experiência que tem sua intensidade alterada de acordo com o tempo, a época, sistemas de justificação ou com valores: "[...] o sofrimento da tortura ou da violação será sempre acompanhado [...] de um colapso dramático da confiança na fidedignidade do mundo social e, com isso, na própria autossegurança" (HONNETH, 2003, 216).

Os outros dois tipos de desrespeito apresentados estão inseridos em um contexto de mudança histórica das sociedades, pois o que se reconhece como lesão moral varia de acordo com os padrões estipulados historicamente e por avanços nas conquistas de reconhecimento. O segundo modo de desrespeito é a privação de direitos. Trata-se do rebaixamento que afeta a autorrelação de autorrespeito moral de uma pessoa. Acontece com a pessoa que se encontra estruturalmente excluída da posse de determinados direitos em uma sociedade: "[...] não lhe é concedida imputabilidade moral na mesma medida que aos outros membros da sociedade" (HONNETH, 2003, 216). Não lhe é concedido status de um parceiro de interação de igual valor, capaz de formar um juízo moral, o que acaba acarretando em um abalo no autorrespeito, isto é, implica na "[...] perda da capacidade de se referir a si mesmo como um parceiro em pé de igualdade na interação com todos os próximos" (HONNETH, 2003, 217). A privação de direitos civis infligida a afrodescendentes e mulheres são exemplos importantes dessa forma de desrespeito.

A terceira forma de desrespeito, a degradação ou ofensa, acontece ao se considerar formas de vida ou modos de crença deficientes ou de menor valor, a tal ponto que se tira das partes atingidas a possibilidade de atribuir valor social, isto é, algum significado positivo, às suas próprias capacidades. $O$ resultado é a perda de autoestima social, a impossibilidade de o cidadão se sentir estimado por suas capacidades e propriedades específicas. Nesse caso, a pessoa é lesada no assentimento social conquistado nas relações solidárias. Minorias, imigrantes, povos aborígenes, crentes, são exemplos de vítimas dessa forma de desrespeito presente nas sociedades modernas. 
Conforme verificado, Hegel e Mead não haviam encontrado o fio condutor que faz da experiência do desrespeito social o móbile capaz de engajar o sujeito em um conflito prático. Faltava em suas teorias a identificação do elemento capaz de informar cognitivamente o sujeito atingido de sua situação social. A tese de Honneth é que existe um elo psíquico que faz a passagem da experiência do sofrimento à ação ativa. Esta função conectiva pode ser desempenhada por reações emocionais negativas, como vergonha ou ira, vexação ou desprezo. Tais reações desencadeiam sintomas psíquicos através dos quais o sujeito percebe que o reconhecimento social lhe é negado de modo arbitrário, isto é, sem justificação. A causa dessas reações é a dependência constitutiva do ser humano em relação ao reconhecimento intersubjetivo, sem o qual ele não alcança uma autorrelação bem sucedida. A negação desse reconhecimento em alguma fase de seu desenvolvimento gera um déficit psicológico que abre espaço para as reações emocionais negativas mencionadas.

O autor parte da psicologia pragmática de John Dewey que trabalha com uma concepção dos sentimentos humanos ligada à teoria da ação. De acordo com ela, os sentimentos negativos surgem com a frustração das expectativas em relação a uma ação efetuada. Em contrapartida, os sentimentos positivos afloram quando um plano de ação é bem sucedido. Dewey fala em dois planos de expectativas: as expectativas instrumentais de êxito, cujo fracasso leva a perturbações "técnicas"; e expectativas normativas de comportamento, cujo fracasso leva a conflitos morais no mundo da vida social.

Honneth destaca especialmente a vergonha ou vexação como sentimento moral de caráter mais aberto. $O$ conteúdo deste sentimento consiste em uma espécie de rebaixamento do valor social que o sujeito supunha ter. Nessa experiência, o ego é violado de duas formas: pela própria pessoa desrespeitada e pelo seu parceiro de interação. $\mathrm{O}$ autor acredita que a experiência de desrespeito nas reações de vergonha pode se tornar o móbile de uma luta por reconhecimento, pois existe um conteúdo cognitivo nessas reações emocionais negativas que pode informar ao sujeito uma injustiça para a qual não se pode reagir de forma neutra, tornando-se o impulso motivacional da luta política. No entanto, esta é uma possibilidade apenas. A transformação do potencial cognitivo presente nesses sentimentos em uma convicção política e moral capaz de motivar uma resistência depende, com efeito, das possibilidades de articulação de movimentos sociais na estrutura política e cultural da sociedade. De acordo com a investigação de Honneth, a tradição da sociologia acadêmica, desde seu surgimento, não deu a devida atenção ao aspecto moral do desrespeito e de seu potencial motivador para o conflito:

[...] foi cortado teoricamente, em larga medida, o nexo que não raro existe entre o surgimento de movimentos sociais e a experiência moral do desrespeito: os motivos para rebelião, o protesto e a resistência foram transformados categorialmente em 'interesses', que devem resultar da distribuição desigual objetiva de oportunidades materiais de vida, sem 
estar ligados, de alguma maneira, à rede cotidiana de atividades morais emotivas (HONNETH, 2003, 255). ${ }^{7}$

O autor busca um paradigma alternativo, orientado pelo modelo de Hegel e Mead, que comprove o nexo entre desrespeito moral e luta social. Honneth diz que o que caracteriza a luta social é o fato de seus objetivos extrapolarem interesses individuais a tal ponto que podem se tornar a base para movimentos coletivos. Se a forma de reconhecimento do amor não contém experiências morais capazes de conduzir à formação de conflitos sociais, pois as vivências não se deixam generalizar para além dos limites da relação primária, as formas do direito e da estima social, por seu turno, se apresentam com uma estrutura moral própria dos conflitos sociais, uma vez que dependem de critérios generalizáveis, pois as experiências de desrespeito que um sujeito sofre nesses casos podem afetar potencialmente outros indivíduos.

Honneth fala de uma complementariedade entre as concepções orientadas para a busca de realização de interesses e as concepções que se baseiam no paradigma do reconhecimento, as quais atribuem o surgimento e o desenrolar dos conflitos sociais às experiências de desrespeito jurídico ou social. Esta complementariedade assume também o papel de correção de um viés utilitarista, no sentido de que tudo o que pode representar um interesse coletivo já se encontra em um "[...] horizonte de experiências morais, em que estão inseridas pretensões normativas de reconhecimento e respeito [...]"(Honneth, 2003, 261-262). Esta visão retificadora pode ajudar na justificação empírica do modelo de conflito defendido pelo autor. Para tal tarefa, vai trabalhar com autores da antropologia social e da sociologia da cultura, os quais desenvolveram uma forma de historiografia capaz de destacar os pressupostos normativos comportamentais reproduzidos por camadas sociais desfavorecidas em conflito.

O primeiro exemplo levantado por Honneth são os estudos de E. P. Thompson sobre os sentimentos morais cotidianos que motivaram as classes oprimidas inglesas a resistir contra o capitalismo industrial. Para ele, "[...] um estado insuportável de subsistência econômica se mede sempre pelas expectativas morais que os atingidos expõem consensualmente à organização da coletividade" (HONNETH, 2003, 263). Quando há uma lesão nesse consenso, ocorre protesto e resistência. No entanto, faltava ainda provar que os conflitos sociais podem ser entendidos segundo o paradigma moral de uma luta por reconhecimento. Ou seja, era preciso demonstrar que a quebra de consenso causa uma privação de reconhecimento social e afeta a autorrelação prática individual. Os estudos de Barrington Moore sobre movimentos revolucionários na Alemanha entre 1848 e 1920 ampliam a concepção de Thompson adicionando um componente da teoria da identidade: a quebra do consenso normativo, representado pelo contrato social implícito, frustra expectativas morais e abala relações de reconhecimento estabelecidas.

Todavia, de acordo com Honneth, a fragilidade desses estudos reside no fato de se referirem a casos episódicos de greves, revoltas ou resistências pacíficas. Para ele, o "[...] abismo entre os processos singulares e o processo evolutivo abrangente só

\footnotetext{
$7 \mathrm{O}$ autor cita muitos autores da sociologia acadêmica: Émile Durheim, Ferdinand Tönnies, Max Weber, Georg Simmel, Robert Park e Ernest Burgess. Cita também as concepções de Karl Marx, Georges Sorel e Jean Paul Sartre como exemplos mal sucedidos de releitura da teoria hegeliana.
} 
pode ser fechado quando a própria lógica de ampliação de relações de reconhecimento vem a ser o sistema referencial das exposições históricas" (HONNETH, 2003, 265). Para tanto, é preciso um modelo de conflito que não apenas explique o surgimento das lutas sociais, mas que também interprete seu processo de formação.

De acordo com o autor, lutas e conflitos históricos particulares só podem demonstrar seu papel na evolução social quando se entende sua importância para um progresso moral em questões de reconhecimento. Destarte, os sentimentos de injustiça e as experiências de desrespeito deixam de ser apenas os móbiles da ação e passam a desempenhar um papel crucial no desdobramento das relações de reconhecimento, sendo responsáveis pelo alargamento ou estreitamento do processo evolutivo da sociedade. É preciso, então, um critério que diferencie motivos progressivos e retrocessivos nas lutas históricas. Tal critério pode ser obtido a partir de uma "[...] antecipação hipotética de um estado comunicativo em que as condições intersubjetivas da integridade pessoal aparecem como preenchidas" (HONNETH, 2003, 268). Este estado é o que Honneth pretende descrever com o seu conceito formal de eticidade.

Honneth concorda com Hegel e Mead que os sujeitos de uma sociedade moderna devem ser reconhecidos como seres autônomos e como seres individualizados. Nesse sentido, uma concepção estreita de moral, como a kantiana, não consegue atender às exigências específicas de reconhecimento ao tratar a todos com o mesmo respeito. Em Kant, a moral tem um sentido universal, todos os sujeitos devem ser tratados como fins em si mesmos e como autônomos. Porém, há na doutrina kantiana da moral uma desvalorização da eticidade, a qual se restringe ao mundo da vida particular na forma de hábitos e costumes, e isso, para Honneth, é danoso. Por outro lado, doutrinas contrárias a Kant, hegelianas ou neo-aristotélicas, pretendem tornar a validade dos princípios morais dependente de concepções éticas, invertendo, assim, a relação entre moralidade e eticidade. Esse também não é o caminho que Honneth quer trilhar, pois não pretende sacrificar o caráter normativo de sua concepção crítica.

"Eticidade", para o autor, é o conjunto das condições intersubjetivas entendidas como pressupostos normativos da autorrealização individual. Como a autorrealização está conectada aos ideais de vida particulares, o autor busca as determinações formais, isto é, capazes de serem universalizadas, e que sejam, ao mesmo tempo, substanciais, isto é, capazes de informar sobre as condições de autorrealização humana. Vimos que sem uma medida de autoconfiança, de autorrespeito e de autoestima não conseguimos alcançar uma autorrelação positiva. Com efeito, esta autorrelação necessita para sua realização de algo mais profundo que a garantia de liberdades negativas, tratando-se de um tipo positivo de liberdade, um sentimento de segurança, o qual só nos é possível experienciar através do reconhecimento.

Nesse sentido, a liberdade de autorrealização depende de pressupostos que não estão à disposição do próprio sujeito humano, visto que ele só pode adquiri-la com ajuda de seu parceiro de interação. Os diversos padrões de reconhecimento representam condições intersubjetivas que temos que

MARTINEZ, Marcela Borges. Axel Honneth e a luta por reconhecimento. Griot : Revista de Filosofia, Amargosa, 
pensar necessariamente quando queremos descrever as estruturas universais de uma vida bem sucedida (HONNETH, 2003, 273).

Honneth consegue, assim, delinear os critérios para sua concepção formal de eticidade: por um lado, os três padrões de reconhecimento são suficientemente formais, pois não se vinculam a determinados ideais de vida; por outro lado, são mais substanciais que uma concepção de autonomia como autodeterminação individual, pois nos informam mais sobre as estruturas universais de uma vida bem sucedida.

\begin{abstract}
As formas de reconhecimento do amor, do direito e da solidariedade formam dispositivos de proteção intersubjetivos que asseguram as condições de liberdade externa e interna, das quais depende o processo de uma articulação e de uma realização espontânea de metas individuais de vida; além disso, visto que não representam absolutamente determinados conjuntos institucionais, mas somente padrões comportamentais universais, elas se distinguem da totalidade concreta de todas as formas particulares de vida na qualidade de elementos estruturais (HONNETH, $2003,274)$.
\end{abstract}

Desta forma, o autor consegue atualizar a teoria do reconhecimento de Hegel e Mead, esclarecendo os pontos obscuros relacionados a dificuldades da época em que foram pensados. Primeiramente, a questão formal perde sua atemporalidade, uma vez que aquilo que pode ser a condição intersubjetiva de uma vida bem sucedida passa a ser considerado uma grandeza histórica e variável. Além disso, ao recorrer à teoria das relações do objeto da psicanálise, o autor consegue posicionar a experiência do amor como a mais básica de todas as formas de vida éticas. Sua concepção de eticidade defende o igualitarismo do amor contra coerções e influências externas, o que torna esse modo de reconhecimento necessário para a segunda condição da integridade pessoal, a relação jurídica.

Outro ponto que merece destaque na versão atualizada de Honneth é a identificação do potencial moral contido no reconhecimento jurídico "[...] capaz de ser desdobrado através de lutas sociais, na direção de um aumento tanto de universalidade quanto de sensibilidade para o contexto" (HONNETH, 2003, 210). A autonomia é um pressuposto da busca pela autorrealização, no entanto, de acordo com o autor, suas condições de aplicação são grandezas passíveis de aperfeiçoamento jurídico, de forma que possam, sem abrir mão de seu caráter universalista, atender melhor à condição particular do indivíduo. É preciso que se pense mais amplamente a relação jurídica, para que ela possa incorporar determinados componentes substanciais; somente assim, esta relação poderá entrar no que ele designa por "rede intersubjetiva de uma eticidade pós-tradicional." Honneth concebe a relação jurídica de forma que ela influencie tanto a relação do amor como as condições da solidariedade. De um lado, a relação jurídica assegura proteção contra a possibilidade de violência física ao indivíduo, presente nas relações emotivas. De outro lado, influencia na solidariedade, pois determina as condições normativas do horizonte de valores formadores da comunidade.

Contudo, a concepção formal de eticidade pretendida por Honneth não estaria completa se não fosse possível avançar em direção à indicação do lugar que os valores materiais devem ocupar. Hegel e Mead já haviam tratado a terceira forma de

MARTINEZ, Marcela Borges. Axel Honneth e a luta por reconhecimento. Griot : Revista de Filosofia, Amargosa, 
reconhecimento de maneira abstrata, desenraizando a estima social do domínio da experiência. Isso faz com que os valores éticos se tornem amplos e plurais, ao ponto de que todo membro da sociedade receba a possibilidade de se sentir estimado. $\mathrm{O}$ que esses autores não perceberam é que esse acréscimo de normatividade indica um potencial evolutivo no padrão de reconhecimento da estima, pois visa à ampliação da igualização e da individualização; além disso, já especifica que os valores que podem ser admitidos como fundadores da comunidade devem ser compatíveis com a autonomia individual de cada um. De acordo com Honneth, ambos, Hegel e Mead, não haviam percebido que suas concepções já continham a chave para a resposta sobre como a solidariedade em condições pós-tradicionais deve ser preenchida no plano do conteúdo.

Pois a tentativa de partir das condições intersubjetivas da integridade pessoal para atingir os universais normativos de uma vida bem sucedida acaba, afinal, incluindo também o padrão de reconhecimento de uma solidariedade social, que só pode nascer das finalidades partilhadas em comum; que essas, por sua parte, estão submetidas às limitações normativas postas com a autonomia juridicamente garantida de todos os sujeitos, é o que resulta de sua posição num tecido de relações, no qual devem coexistir com os outros dois padrões de reconhecimento do amor e do direito (HONNETH, 2003, 279). 


\section{Referências bibliográficas}

HEgEL, G. W. F. La Phénoménologie de l'Esprit. Paris, Editions Montaigne, 1941. System of Ethical Life. New York, State University Press, 1979. Elements of a Philosophy of Right. Cambridge, University Press,

1991.

HONNETH, A. Luta por reconhecimento: a gramática moral dos conflitos sociais. São Paulo: Ed. 34, 2003.

KANT, I. "Fundamentação da metafísica dos costumes". Kant. São Paulo: Abril Cultural, 1980. v.2. (Os Pensadores).

Crítica da razão prática. São Paulo: Martins Fontes, 2002.

RICOEUR, P. Percurso do Reconhecimento. São Paulo: Loyola, trad. Nicolas Nyimi Campanário, 2006.

VAN DEN BRINK, B., OWEN, D. (Eds). Recognition and power: Axel Honneth and the tradition of critical social theory. New York: Cambridge University Press, 2007.

Autor(a) para correspondência: Marcela Borges Martinez, Instituto Federal de Educação, Ciência e Tecnologia do Rio de Janeiro, Estrada Washington Luís, Sape, CEP 24310-000, Niterói - RJ, Brasil. marcela.filosofia@gmail.com 